\title{
Efeito das informações e características da embalagem na expectativa e aceitação de café solúvel adicionado de café torrado micronizado
}

\author{
Impact of the information and package characteristics on the expectation and \\ acceptance of a soluble coffee with added micronized roasted coffee
}

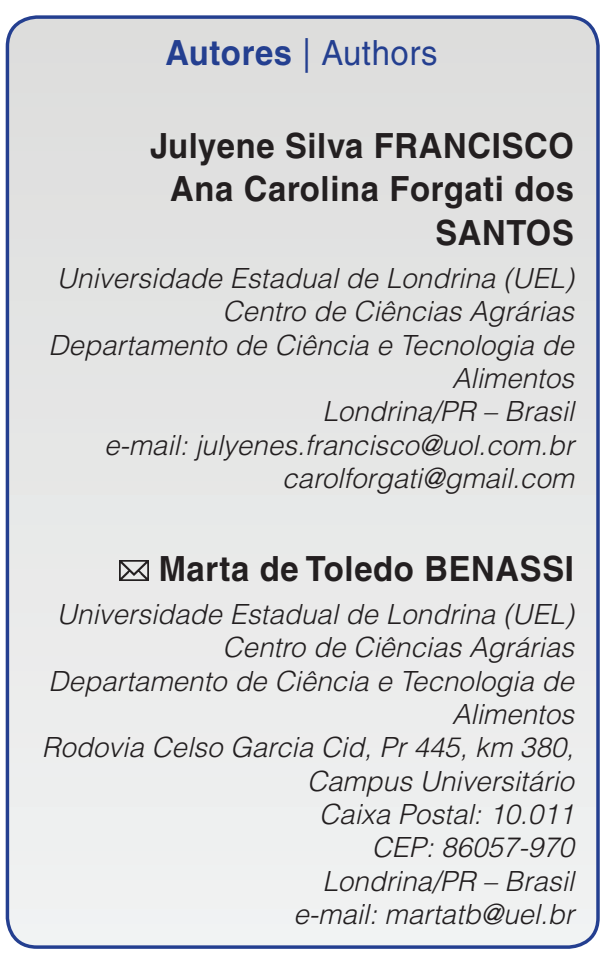

Autor Correspondente / Corresponding Author

Recebido: Abr. 24, 2014

Aprovado: Out. 23, 2014

\section{Resumo}

Foi recentemente lançado, no Brasil, um café solúvel adicionado de café torrado e moído micronizado (finamente moído), mas não se observaram na literatura trabalhos que avaliem a reação do consumidor brasileiro frente a esse novo conceito de produto. Assim, o objetivo do estudo foi verificar o impacto das informações e das características da embalagem sobre a expectativa e aceitação de um café solúvel adicionado de café torrado micronizado. Dois cafés solúveis comerciais da mesma marca, um convencional e outro adicionado de café torrado micronizado (aqui denominado produto novo), foram avaliados através das técnicas grupo de foco e avaliação da expectativa, comparando-se os produtos e as embalagens correspondentes. A embalagem do café solúvel adicionado de café torrado micronizado foi menos apreciada nas sessões de grupo de foco. O produto novo não foi facilmente identificado como sendo um café solúvel, mostrando a necessidade de deixar claro o conceito do produto na embalagem. A bebida do produto novo mostrou uma boa aceitação sensorial, similar ao café solúvel convencional $(p>0,05)$. Somente para o produto convencional a aceitação foi influenciada por fatores extrínsecos (informações e características da embalagem), o consumidor assimilou a alta expectativa gerada pela maior familiaridade com o produto e/ou embalagem e aumentou sua aceitação na avaliação informada. Conclui-se que a embalagem do café solúvel adicionado de café torrado micronizado deve apresentar maior similaridade com a embalagem do produto convencional no que diz respeito a cores e ilustrações. A embalagem deve ainda conter informações claras quanto aos diferenciais do produto, tais como proximidade sensorial com o produto torrado e moído e a facilidade no preparo do café solúvel.

Palavras-chave: Embalagem; Expectativa; Grupo de foco; Aceitação sensorial.

\section{Summary}

Recently a soluble coffee with added micronized (finely ground) roasted coffee was launched in Brazil, but no studies evaluating the reaction of Brazilian consumers to this new product concept could be found in the literature. Thus, the aim of this study was to evaluate the impact of the information and package characteristics on the expectation and acceptance of a soluble coffee with added micronized roasted coffee. Two commercial products from the same brand, one a conventional soluble coffee and the other a soluble coffee with added micronized roasted coffee (new product), were evaluated by the techniques of Focus group and expectation evaluation, comparing the products and their corresponding packages. The package of instant coffee with micronized roasted coffee was less appreciated in the Focus group sessions. The new product was not easily identified as a soluble coffee, showing the need to clarify the concept of the product on the package. The brew of the new product showed good sensory acceptance, similar to that of conventional soluble coffee $(p>0.05)$. The acceptance was only influenced by extrinsic factors (information and package characteristics) in the case of the conventional product, the consumers assimilating the high expectations generated by greater familiarity with the product and/or package, and increasing their acceptance on the informed evaluation. It was concluded that the package of soluble coffee with added micronized roasted coffee should be more similar to that of the conventional product with respect to colour and illustrations. The package should present clear information about the differentials of the product, such as greater sensory proximity with the ground roasted coffee and ease in preparing the soluble coffee. 


\section{Introdução}

O Brasil, atualmente responsável por 30\% do mercado internacional de café, é o maior produtor e o segundo mercado consumidor mundial (CONAB, 2014). Em pesquisas de tendências de consumo de café realizadas entre 2003 e 2010 pela Associação Brasileira da Indústria de Café (ABIC), foi citado que, no ano de 2010, 96\% dos entrevistados consumiam café torrado e moído. Portanto, o café é um produto inserido nos hábitos do brasileiro com alta penetração. Entretanto, para sustentar e ampliar essa posição, destaca-se a necessidade da manutenção do aroma e sabor característicos do produto, a reintrodução do hábito como alternativa no café da manhã ou no lanche de crianças e o lançamento de produtos prontos (ABIC, 2010).

A indústria de alimentos tem o desafio de identificar novos hábitos de consumo, e assim ressalta-se o constante crescimento do consumo de produtos de café com maior valor agregado, como gourmet $\mathrm{e}$ premium (BARBOSA et al., 2010; ABIC, 2010; BUREAU DE INTELIGÊNCIA COMPETITIVA DO CAFÉ, 2014), o que evidencia uma exigência do consumidor quanto à qualidade (ABIC, 2010; BUREAU DE INTELIGÊNCIA COMPETITIVA DO CAFÉ, 2014).

O primeiro contato do consumidor com o produto é por meio da sua embalagem. Tradicionalmente, empregam-se em estudos de consumidor, testes de aceitação ou preferência pelo produto, entretanto, avaliar a embalagem é essencial na determinação dos critérios do consumidor para a escolha, decisão de compra e consumo de um produto (DELLA LUCIA et al., 2007). Técnicas como grupo de foco e de estudo da expectativa têm sido empregadas para avaliar a influência da embalagem de alimentos sobre a intenção de compra dos consumidores. O grupo de foco consiste em uma discussão em grupo, coordenada por um mediador, que apresenta 0 assunto de interesse e permite aos participantes explicar as razões para suas preferências (DUTCOSKY, 2013). O estudo da expectativa determina a aceitação de produtos e suas respectivas embalagens, bem como permite avaliar a expectativa gerada pelas características da embalagem e a sua influência sobre a aceitação sensorial (NORONHA et al., 2005).

O desenvolvimento de um novo produto requer uma avaliação específica da expectativa gerada e de como os atributos da embalagem impactam a intenção de compra. Em 2012, houve o lançamento de um produto no Brasil com um conceito bastante diferenciado: café solúvel adicionado de café torrado e moído micronizado (BALIEIRO, 2012). O produto é comercializado de forma limitada no mercado, e não se observaram trabalhos na literatura que avaliem a reação do consumidor brasileiro frente a essa proposta de tentar conciliar a praticidade de preparo do café solúvel com o aroma e sabor do café torrado e moído.

Portanto, o objetivo do estudo foi verificar o impacto das informações e das características da embalagem sobre a expectativa e aceitação de um café solúvel adicionado de café torrado micronizado.

\section{Material e métodos}

\subsection{Material}

Para comparação com o produto novo no mercado brasileiro, café solúvel adicionado de café torrado micronizado, foi escolhido um café solúvel convencional de grande comercialização no Brasil. Os dois produtos comerciais utilizados foram da mesma marca: o café solúvel $\mathrm{A}$ foi o produto convencional e aglomerado e o produto $\mathrm{B}$ correspondeu ao café solúvel em pó adicionado de café torrado e moído micronizado. Os produtos foram adquiridos no mercado brasileiro, em supermercados, no período de fevereiro de 2013

Para determinar os atributos das embalagens que causam impacto na aceitação do consumidor, pela técnica de grupo de foco avaliaram-se três embalagens: duas do produto A (embalado em vidro - EAv e em sachê plástico laminado - EAs) e uma do produto $B$ (embalado em lata de aço - EB) (Tabela 1). Para o produto A existia no mercado disponibilidade de dois tipos de embalagem (em vidro e em sachê).

Para avaliação da expectativa do consumidor, foram empregadas as bebidas dos produtos $\mathrm{A}$ e $\mathrm{B}$, e as embalagens EAv e EB (Tabela 1).

\subsection{Avaliação sensorial}

Todos os participantes do estudo sensorial foram informados quanto aos produtos e aos procedimentos dos testes e expressaram sua concordância em participar das avaliações conforme descrito no projeto aprovado e cadastrado no Sistema Nacional de Ética em Pesquisa (Certificado de Apresentação para Apreciação Ética $n^{\circ}$ 07753412.7.0000.5231).

\subsubsection{Avaliação qualitativa das embalagens e do conceito do produto café solúvel adicionado de café torrado e moído micronizado pelo grupo de foco}

Os 32 participantes, da cidade de Londrina, formaram quatro grupos com oito julgadores em cada, e para caracterização da equipe responderam um questionário sobre consumo de café, costume de leitura de rótulos de alimentos e hábitos de compra em supermercados. Dois grupos foram compostos por mulheres, na faixa etária de 24 a 49 anos, e 30 a 70 anos, com grande responsabilidade de compras para 
Tabela 1. Descrição das embalagens de cafés solúveis comerciais utilizadas nas sessões de grupo de foco.

\begin{tabular}{|c|c|c|}
\hline Produto & Embalagem & Descrição do painel \\
\hline \multirow{2}{*}{$\begin{array}{c}\text { A } \\
\text { Café solúvel } \\
\text { aglomerado }\end{array}$} & $\begin{array}{c}\text { EAv } \\
\text { Embalagem } \\
\text { de vidro alta, } \\
\text { de formato } \\
\text { acinturado, com } \\
\text { tampa de plástico } \\
\text { vermelha e } \\
\text { arredondada }\end{array}$ & $\begin{array}{l}\text { Painel frontal da embalagem: rótulo de papel com fundo na cor vermelha e ilustrado } \\
\text { na metade inferior com grãos de café torrado e uma xícara grande (externamente } \\
\text { vermelha e dourada e internamente branca) entre eles, contendo café com espuma na } \\
\text { borda, e fumaça em movimento ascendente; informações nas cores branca, amarela } \\
\text { e preta: marca, café solúvel granulado, peso líq. } 100 \mathrm{~g} \text {, forte e tradição. Painel detrás } \\
\text { da embalagem: rótulo de papel com fundo na cor vermelha e ilustração central de } \\
\text { um bule vermelho e uma colher despejando respectivamente leite e o produto a uma } \\
\text { xícara (igual à evidenciada no painel frontal); informações nas cores branca, amarela } \\
\text { e preta: modo de preparo (com água e com leite) e ilustrações de três pequenos } \\
\text { quadros contendo as informações adjacentes: SAC*, café é uma fonte natural de } \\
\text { antioxidantes e dica de consumo com leite. }\end{array}$ \\
\hline & $\begin{array}{c}\text { EAs } \\
\text { Embalagem de } \\
\text { plástico laminado } \\
\text { vermelho, tipo } \\
\text { sachê, para uso } \\
\text { como refil }\end{array}$ & $\begin{array}{l}\text { Porção frontal: ilustração de grãos de café torrado e uma xícara grande (externamente } \\
\text { vermelha e dourada e internamente branca) entre eles, contendo café com espuma na } \\
\text { borda, e fumaça em movimento ascendente; informações nas cores branca, amarela } \\
\text { e preta: marca, café solúvel granulado, peso líq. } 50 \mathrm{~g} \text {, forte, tradição e abra aqui. } \\
\text { Painel detrás: ilustração, à direita, de um bule vermelho e uma colher despejando } \\
\text { respectivamente leite e o produto a uma xícara (igual à evidenciada no painel frontal); } \\
\text { informações nas cores branca, amarela e preta: modo de preparo (com água e } \\
\text { com leite), fácil de preparar e ilustrações de três pequenos quadros contendo as } \\
\text { informações adjacentes: SAC*, café é uma fonte natural de antioxidantes e dica de } \\
\text { consumo com leite. }\end{array}$ \\
\hline $\begin{array}{c}\text { B } \\
\text { Café solúvel em } \\
\text { pó adicionado } \\
\text { de café torrado } \\
\text { e moído } \\
\text { micronizado }\end{array}$ & $\begin{array}{c}\text { EB } \\
\text { Embalagem } \\
\text { cilíndrica baixa } \\
\text { e de formato } \\
\text { acinturado, tipo } \\
\text { lata de aço, com } \\
\text { fundo na cor } \\
\text { prata, tampa } \\
\text { arredondada } \\
\text { de plástico } \\
\text { na cor laranja } \\
\text { e rotulagem } \\
\text { impressa }\end{array}$ & $\begin{array}{l}\text { Painel frontal da embalagem: na porção inferior informações café solúvel e café } \\
\text { torrado e moído e peso líquido } 100 \mathrm{~g} \text {, na cor marrom, e no centro ilustração de } \\
\text { três formas geométricas sobrepostas na ordem - retângulo alaranjado contendo as } \\
\text { informações: } 100 \% \text { café, na cor branca, e } 100 \mathrm{~g} \text { de (nome do produto) rende igual } \\
\text { a } 500 \text { g de café torrado e moído, na cor marrom; hexágono marrom contendo as } \\
\text { informações na cor branca: marca e nome do produto; e círculo pequeno de cor } \\
\text { amarela, branca e marrom, com um grão de café desenhado no centro e a informação } \\
\text { com café microgranulado inscrita na borda. Painel detrás: informação fácil de } \\
\text { preparar, na cor laranja; ilustrações: jarra com leite, xícara com café, dois quadros na } \\
\text { cor marrom com o modo de preparo (com água e com leite) escrito nas cores branca } \\
\text { e laranja e quadros com as informações adjacentes: SAC* (na cor branca sobre } \\
\text { fundo marrom), café é uma fonte natural de antioxidantes (na cor marrom sobre fundo } \\
\text { laranja) e texto, na cor marrom sobre fundo laranja, de apelo ao diferencial do produto } \\
\text { (mistura dos cafés solúvel e torrado e moído). }\end{array}$ \\
\hline
\end{tabular}

${ }^{\star} \mathrm{SAC}=$ serviço de atendimento ao consumidor.

casa. O terceiro grupo foi constituído por homens, na faixa de 20 a 49 anos, com menor responsabilidade pela aquisição de alimentos do lar, e o último grupo foi formado por quatro casais (4 homens e 4 mulheres) que dividiam a responsabilidade pelas compras em casa. Quatro sessões com duração máxima de 70 minutos foram conduzidas por um moderador que contou com o auxílio de assistentes para a anotação das opiniões. As sessões foram gravadas em áudio para facilitar a transcrição.

Nos grupos, cada embalagem e seu respectivo rótulo foram avaliados individualmente por todos os participantes, e o moderador formulou questões referentes às características visuais e informações encontradas nas embalagens, a fim de estimular os julgadores a expressar suas opiniões. Os pontos discutidos foram levantados conforme o contexto e abordados de acordo com a dinâmica da avaliação.

1. Você observa os rótulos/embalagens dos produtos que consome?

2. O que mais chama sua atenção num rótulo/ embalagem de café?

3. Que importância você dá ao material da embalagem e a facilidade de abrir/manter fechada a embalagem?

4. Que importância você dá à possibilidade de visualizar o produto? 
5. Se estivesse em um rótulo de café solúvel, a informação: "café solúvel adicionado de café torrado e moído", você compraria?

6. Qual aparência/características você espera de um café solúvel adicionado de café torrado e moído?

7. O que você considera importante destacar no rótulo deste produto?

8. Você gostaria de ver mais alguma informação e/ ou ilustração no rótulo que não foi apresentada?

9. Você pagaria mais por esse produto?

\subsubsection{Avaliação da expectativa do consumidor}

Cem pessoas consumidoras de café entre alunos, professores e funcionários de duas Instituições de ensino superior de Londrina/PR foram recrutadas. A equipe foi composta majoritariamente por pessoas com idade inferior a 35 anos (91\%), sendo que as mulheres representaram a maior proporção (67\%). O grupo apresentava diferentes graus de instrução e renda familiar, e se destacava pelo alto consumo de café solúvel (61\%), comparativamente à média nacional (17\%) (ABIC, 2010). Os demais julgadores $(39 \%)$ consumiam regularmente apenas café coado/filtrado. Entre os consumidores de café solúvel, $82 \%$ relataram consumir também café filtrado. Os consumidores do café solúvel, quando solicitados a designar qual o tipo de embalagem mais comumente comprada, citaram com maior frequência o recipiente de vidro (54\%).

O teste foi conduzido em Laboratório de Análise Sensorial, em cabines individuais sob luz branca, compreendendo três sessões, com intervalos de, no mínimo, dois dias entre cada sessão. Foram avaliadas as bebidas dos produtos $\mathrm{A}$ e $\mathrm{B}$ e as respectivas embalagens, EAv e EB.

As bebidas foram preparadas de acordo com o recomendado por Kobayashi e Benassi (2012). Empregou-se a proporção de 1,4 g de café solúvel por $50 \mathrm{~mL}$ de água filtrada a $95^{\circ} \mathrm{C}$, e os cafés foram adoçados utilizando-se 9,5\% de sacarose. Após o preparo, as amostras foram armazenadas em garrafas térmicas e mantidas por no máximo $2 \mathrm{~h}$ até serem servidas, garantindo-se a temperatura de $70^{\circ} \mathrm{C}$ (OLIVEIRA et al., 2009). Aproximadamente $30 \mathrm{~mL}$ das bebidas foram servidos em copos de isopor descartáveis.

As amostras foram codificadas com número de três dígitos aleatórios e apresentadas de forma monádica e sequencial, com delineamento de blocos completos balanceados e ordem de apresentação aleatorizada.

Os consumidores avaliaram a aceitação em três diferentes sessões: 1) avaliação cega; 2) avaliação da expectativa; 3) avaliação informada. Uma escala hedônica híbrida de $10 \mathrm{~cm}$, ancorada nas extremidades e no meio pelas expressões, "desgostei extremamente", "não gostei, nem desgostei" e "gostei extremamente" (VILLANUEVA et al., 2005), foi utilizada nas três sessões.

$\mathrm{Na}$ avaliação cega $(\mathrm{C})$, os consumidores avaliaram somente as bebidas.

$\mathrm{Na}$ avaliação da expectativa (E), foi avaliada a aceitação dos produtos analisando-se apenas as embalagens. Esse procedimento permitiu que 0 consumidor avaliasse tanto os atributos da embalagem quanto as informações presentes no rótulo.

$\mathrm{Na}$ avaliação informada (I), o consumidor expressou sua aceitação quanto à bebida, considerando que esta era proveniente do produto contido na embalagem apresentada junto.

As notas médias de aceitação foram calculadas em cada sessão (C, E e I), e para comparação aplicou-se o teste $t$ ao nível de $5 \%$ de significância. As diferenças entre as notas sob os variados regimes de informação, I-E, E-C (grau de desconfirmação) e I-C, para cada produto foram determinadas (BEHRENS et al., 2007), e avaliadas ao nível de $5 \%$ de probabilidade utilizando-se o teste $t$. A presença de assimilação foi avaliada através da regressão obtida pela relação entre as diferenças I-C e E-C (BEHRENS et al., 2007; LANGE et al., 1999; STEFANI et al., 2006). As análises estatísticas foram feitas utilizando-se o programa Statistica 7 (STATSOFT, 2006).

\section{Resultados e discussão}

\subsection{Avaliação qualitativa das embalagens e do conceito do produto café solúvel adicionado de café torrado e moído micronizado pelo grupo foco}

A equipe, formada majoritariamente por mulheres $(62,5 \%)$, constituiu-se por indivíduos na faixa etária acima de 30 anos: $25 \%$ entre 30 e 39 anos e $53 \%$ com idade superior a 50 anos. Os membros da equipe apresentaram alta escolaridade (68\% com ensino superior completo) e com renda pessoal entre um e dez salários mínimo (75\%). Os participantes eram total ou parcialmente responsáveis pelas compras de casa e compravam café torrado e moído; metade dos participantes comprava também café solúvel e cappuccino.

No questionário de recrutamento, a maior parte dos participantes (59\%) declarou ler os rótulos "às vezes ou ocasionalmente", sendo os itens mais verificados o prazo de validade e a marca ( $91 \%$ e $75 \%$ respectivamente). Della Lucia et al. (2009), trabalhando com embalagens de café, também observaram que a data de validade e a marca estão entre as características mais observadas no momento da compra. Interessante mencionar que, durante 
todas as sessões, muitos participantes declararam não ter o hábito de leitura de rótulos por comprarem produtos de marca conhecida e habitualmente consumidos.

As respostas mais frequentes nos quatro grupos de foco foram sumarizadas na Tabela 2. Com relação ao formato, a forma acinturada das embalagens EAv e EB (Tabela 1) agradou por facilitar a abertura dos recipientes, e os julgadores destacaram a embalagem de vidro (EAv) quanto à beleza, delicadeza e praticidade para o uso frequente e armazenamento (Tabela 2). O resultado é concordante com outros estudos da literatura (CORSO, 2013; KOBAYASHI, 2012) sobre a intenção de compra de cafés solúveis com consumidores brasileiros, que observaram que para os recipientes de vidro o formato acinturado foi preferido e considerado moderno. Os julgadores consideraram que o formato da lata de aço (EB) (Tabela 1) não remeteu ao consumidor a ideia de um café solúvel (Tabela 2).

Os participantes reportaram que tinham interesse em visualizar o produto no momento da compra, principalmente por considerarem que, no caso do café solúvel, a alteração da aparência pode estar relacionada à perda de qualidade. Um segundo fator muito comentado, quanto ao material da embalagem, foi a possibilidade de vedação, e novamente a embalagem de vidro foi considerada a melhor (Tabela 2). Portanto, a transparência e a vedação da embalagem de vidro (EAv) foram muito apreciadas pelos julgadores. Corso (2013) relatou também em seu estudo a relevância dada à visualização de café solúvel.

Quanto ao tipo de café solúvel, observou-se preferência dos indivíduos pelo produto aglomerado (A). Kobayashi (2012), trabalhando com grupo de foco para cafés solúveis comerciais brasileiros, citou que a maioria dos participantes gostava da aparência do café solúvel granulado escuro, mas não gostava de visualizar um produto em pó ou liofilizado (mais claro). A aparência "em pó" do produto B não foi criticada, uma vez que já era esperada por grande parte dos julgadores, que associava café solúvel em lata com essa característica (Tabela 2). Isso demonstrou que, nesse caso, o material da embalagem foi bem escolhido para o produto em questão.

A cor vermelha e o marrom das embalagens do café solúvel convencional (EAv e EAs) (Tabela 1) foram considerados muito atrativos e tradicionalmente associados aos produtos de café (Tabela 2). Estudos anteriores com consumidores brasileiros relataram a mesma preferência pelas cores marrons e avermelhadas para rótulos de diferentes produtos de café (CORSO, 2013; DELLA LUCIA et al., 2009; KOBAYASHI, 2012).

Houve comentários divergentes quanto ao emprego da combinação de cores (prata, marrom, alaranjado e branco) da embalagem EB (Tabela 1). Alguns julgadores apreciaram e ressaltaram uma aparência moderna, inovadora e requintada proporcionada pelas cores do rótulo, no entanto a maior parte dos participantes considerou a embalagem fria e menos atrativa devido ao uso de cores "apagadas" (Tabela 2). Assim como observado para o formato, a cor prata predominante na embalagem EB favoreceu a associação com outros produtos (cappuccino ou achocolatados), o que segundo proposto pela equipe poderia ser modificado com o uso de cores fortes (preto, marrom-escuro, vermelho e/ou amarelo). Apesar da interferência da cor da embalagem na intenção de compra de cafés torrados e moídos relatada por Della Lucia et al. (2009), Kobayashi (2012) observou que essa característica não foi determinante para a preferência em cafés solúveis.

Quando levantadas questões sobre ilustrações, notou-se em todos os grupos um consenso: os participantes gostaram de ver em rótulos de produtos de café figuras de grãos torrados e de xícara contendo café com espuma e fumaça/vapor na forma de foto, pois dão a impressão de um produto de boa qualidade, gostoso e recém-preparado (Tabela 2). Informações similares são citadas na literatura em outros estudos com café solúvel com consumidores brasileiros (CORSO, 2013; KOBAYASHI, 2012). A embalagem em lata (EB) foi menos apreciada com respeito a essa característica por apresentar poucas ilustrações e em forma de desenho (Tabelas 1 e 2).

O conteúdo e a forma de apresentação das informações (letras de tamanho adequado e de cores contrastantes com o fundo) das embalagens Av e As foram muito apreciados (Tabela 2). A presença da denominação "forte", destacada em ambas as embalagens, agradou os participantes, bem como a expressão "tradição", que, segundo eles, remete para um produto conhecido e aprovado, e está associada com "momentos em família". Kobayashi (2012) relatou o efeito positivo do termo "tradicional" na embalagem de cafés solúveis, devido à associação que os consumidores faziam com o café do dia a dia e/ou a um grau de torra adequado. Somente para a data de validade, um dos itens mais verificados ao comprar, destacou-se melhor visibilidade na embalagem tipo sachê (EAs) (Tabela 2).

Quanto ao produto B, muitos dos participantes mencionaram dúvidas quanto ao preparo e possível formação de borra, considerando-se dessa forma que essas informações poderiam aparecer com maior destaque (Tabela 2). Corso (2013), aplicando a técnica grupo de foco na avaliação de cafés solúveis enriquecidos com antioxidantes naturais do café verde, constatou que uma marca bem conhecida e forte é crucial para aceitação de um novo produto. No presente estudo, cafés solúveis de apenas uma marca muito conhecida foram avaliados, porém, quando solicitados 
Tabela 2. Síntese dos comentários mais frequentes relativos às embalagens de vidro (EAv) e sachê (EAs) do produto A e embalagem de aço do produto $B(E B)$, avaliadas nas sessões de grupo de foco.

Característica E Respostas

O design com curvas torna a embalagem bonita, delicada e elegante. A forma acinturada da embalagem facilita abrir. Os cantos e tampa arredondados além de visualmente charmosos

Formato

EAv

(recipiente)*

tons

EB facilitam a abertura da embalagem. O formato é prático para o uso frequente e facilita o armazenamento da embalagem. O formato agrada, porém um recipiente de vidro mais baixo, mais largo e com abertura maior na boca poderia facilitar a retirada do produto quando 0 conteúdo está acabando.

O formato está associado a cappuccino e não remete a um café solúvel. O formato acinturado da embalagem facilita sua abertura.

Para café solúvel, a visualização da aparência do produto é fundamental no momento da compra; a embalagem de vidro é ótima, devido principalmente à transparência que possibilita a

EAv visualização do produto e maior segurança no instante da compra. O café solúvel armazenado em embalagem de vidro é mais bem conservado; a vedação é melhor em embalagens de vidro do que em latas; café solúvel contido em lata perde sua aparência característica com menor

Material da embalagem/ visualização do produto tempo de armazenamento.

A embalagem tipo sachê é prática, mas a compra é feita para uso como refil de produto para ser posteriormente acondicionado em embalagem de vidro; para o armazenamento de café solúvel, o sachê não é bom devido à impossibilidade de vedação da embalagem depois de aberta. Nas gôndolas, o sachê é ruim por não possibilitar a visualização do produto.

A lata pode ser indicativa do tipo do produto, pois café solúvel em pó normalmente é embalado em lata. A impossibilidade de visualização do conteúdo é um ponto negativo. Café solúvel armazenado em lata não tem sua aparência bem conservada por muito tempo, pois endurece rapidamente. A vedação em embalagens de lata depois de abertas não é boa.

As cores vermelha e marrom são muito atrativas e bastante associadas aos produtos de café; o

EAv/EAs vermelho é interessante por proporcionar maior nitidez à data de validade do produto (inscrita na

Cor (tampa/ rótulo)

EB

EAv/EAs

Ilustrações

EB

EAv cor branca).

A cor prata enobrece o produto, e proporciona aparência elegante, moderna, inovadora, requintada, e associada com um produto caro. A cor é apagada, não chama atenção, deixou a embalagem "fria", não atraente. A cor predominante prata da embalagem ofusca a visão e dificulta a leitura das informações contidas.

Rótulo ótimo, "dá impressão de produto gostoso". A ilustração da xícara contendo café com espuma e a fumaça subindo é muito atraente e capaz de despertar no consumidor a vontade de "tomar um cafezinho"; a fumaça saindo do café na xícara está muito associada a embalagens de produtos de café.

A embalagem é muito "limpa", sinto falta das imagens de xícara com café saindo fumaça e grãos torrados; as poucas ilustrações presentes na embalagem não chamam atenção. Não se destacaria nas gôndolas por apresentar somente desenhos.

Informações como "forte" e "extra-forte" são essenciais, pois na maioria das vezes influenciam a decisão pela compra ou não do produto. A atribuição do termo "tradição" a este café solúvel foi muito conveniente, pois traz à memória lar, família, fazenda, algo antigo, seguro, conhecido e aprovado.

As mesmas da EAv. Informação "Café Solúvel Granulado" não está legível devido o pequeno tamanho da letra, dificultando a identificação do produto já que o material da embalagem

EAs (plástico laminado) não possibilita sua visualização. Data de validade bem destacada, ponto

Informações positivo no momento da compra.

Falta deixar claro no rótulo a característica diferenciada do produto (adição de café torrado e moído ao solúvel). A praticidade no preparo e as particularidades em termos de aroma deveriam estar mais evidentes e de forma clara. A informação "100\% café" é desnecessária, porém pode ter sido considerada no rótulo pelo fato da lata remeter a outros produtos, como cappuccino; a informação "100\% café" gera a impressão de que o produto é um café selecionado ou de melhor qualidade. Data de validade mal localizada (no fundo da embalagem) e com pouco destaque; as informações presentes no rótulo deveriam estar mais legíveis, com letras maiores.

${ }^{*}$ Considera respostas atribuídas apenas às embalagens de vidro (EAv) e aço (EB) 
Efeito das informações e características da embalagem na expectativa e aceitação de café solúvel torrado micronizado FRANCISCO, J. S. et al.

a informar seu interesse quanto à compra do novo produto (café solúvel adicionado de café torrado e moído micronizado), muitos dos participantes não conseguiram definir se estariam interessados. A dificuldade relatada por eles em identificar, pela embalagem, o produto como sendo um café solúvel parece ter influenciado nesse comportamento.

Tendo em vista a necessidade de deixar claro o conceito e o diferencial do produto, no geral os participantes destacaram que as particularidades como a proximidade sensorial com o produto torrado e moído e a facilidade no preparo do café solúvel deveriam estar mais legíveis e mais destacadas. Portanto, maior clareza nas informações e a presença de ilustrações e cores mais associadas pelo consumidor com produtos de café poderiam favorecer o interesse pelo novo produto (B).

\subsection{Avaliação da expectativa quanto ao produto café solúvel adicionado de café torrado e moído micronizado}

Na Tabela 3 estão as notas médias observadas para os dois produtos de café solúvel sob condições de avaliação cega (C), avaliação da expectativa (E) e avaliação informada (I). Os produtos apresentaram médias superiores a 6,7 (em uma escala de 10) nas três sessões realizadas, demonstrando que houve aceitação tanto na percepção sensorial (C), quanto na expectativa (E) gerada pela ideia de um café solúvel adicionado de café torrado e moído.

Não houve diferença na aceitação ( $p>0,05)$ dos produtos, na avaliação cega $(\mathrm{C})$, mas o produto solúvel convencional foi mais aceito que o adicionado de café torrado e moído micronizado tanto na avaliação da expectativa (E) quanto na avaliação informada (I) (Tabela 3). Foi observado que nas avaliações em que o consumidor teve acesso à embalagem, o produto $A$, que utilizava uma embalagem de vidro, citada como mais frequentemente comprada que a lata, foi mais aceito.

A diferença entre as notas médias esperadas e reais (E-C) foi avaliada e ocorreu comportamento diferenciado entre as amostras uma vez que só foi encontrada diferença positiva $(p<0,05)$ para o produto A (Tabela 4).

Somente para o produto A foi observada diferença significativa $(p<0,05)$ para $1-C$ (Tabela 4$)$. Segundo Lange et al. (1999) e Stefani et al. (2006), uma diferença I-C significativa demonstra o efeito das informações sobre a avaliação da aceitação, e nesse caso há duas possibilidades: a) $(\mathrm{I}-\mathrm{C}) /(\mathrm{E}-\mathrm{C})<0$, revelando um efeito de contraste; ou b) $(\mathrm{I}-\mathrm{C}) /(\mathrm{E}-\mathrm{C})>0$, revelando um efeito de assimilação. A relação entre as diferenças I-C e E-C foi determinada para o produto A e apresentada na Figura 1.

Para o café solúvel convencional (A) observou-se uma desconfirmação negativa (produto considerado pior que o esperado, E > C) e a assimilação da expectativa (Tabela 4 e Figura 1). Portanto, o consumidor assimilou a alta expectativa gerada pela maior familiaridade com o produto, ou mesmo pela embalagem, devido ao material (vidro), aparência e informações no rótulo, e aumentou sua aceitação na avaliação informada (Tabelas 3 e 4).

Os efeitos significativos observados para a diferença I-E (Tabela 4) indicaram que a assimilação não foi completa (LANGE et al., 1999). A assimilação sob desconfirmação negativa (56\%) foi o principal efeito das características da embalagem sobre a aceitabilidade do produto, confirmando um resultado frequente na literatura (ARRUDA et al., 2006; BEHRENS et al., 2007; CAPORALE e MONTELEONE, 2004; CORSO, 2013; DELIZA et al., 2000; LANGE et al., 1999). Onze indivíduos (11\%) seguiram o modelo de contraste, que ocorre quando a

Tabela 3. Nota média de aceitação dos cafés solúveis, convencional (A) e adicionado de café torrado e moído micronizado (B), obtidos sob diferentes conjuntos de informação para a equipe $(n=100)$.

\begin{tabular}{cccc} 
Produto & Avaliação cega (C) & Avaliação da expectativa (E) & Avaliação informada (I) \\
A & 6,7 & 8,4 & 7,7 \\
B & 7,1 & 7,2 & 6,9 \\
\hline
\end{tabular}

* Valores em cada coluna seguidos de mesma letra não são significativamente diferentes entre si $(p>0,05)$ segundo o teste tem amostras pareadas.

Tabela 4. Efeito da expectativa sobre a aceitação $(n=100)$ dos cafés solúveis, convencional $(A)$ e adicionado de café torrado e moído micronizado (B).

\begin{tabular}{|c|c|c|c|c|c|c|}
\hline \multirow{2}{*}{ Amostra } & \multicolumn{2}{|c|}{$(E-C)^{*}$} & \multicolumn{2}{|c|}{$(\mathrm{I}-\mathrm{C})^{*}$} & \multicolumn{2}{|c|}{$(\mathrm{I}-\mathrm{E})^{*}$} \\
\hline & M & $\mathbf{p}$ & M & p & M & p \\
\hline \multirow{2}{*}{ A } & 1,69 & 0,00 & 0,99 & 0,00 & $-0,70$ & 0,00 \\
\hline & desconfirmação & negativa & assimilação & & & \\
\hline \multirow{2}{*}{ B } & 0,05 & 0,82 & $-0,20$ & 0,32 & & \\
\hline & confirmação & & & & & \\
\hline
\end{tabular}

* Diferenças médias (M) seguidas por um valor de p inferior a 0,05 são consideradas diferentes de zero, de acordo com o teste $t$ para amostras relacionadas; C: nota da avaliação cega; E: nota da avaliação da expectativa; I: nota da avaliação informada. 


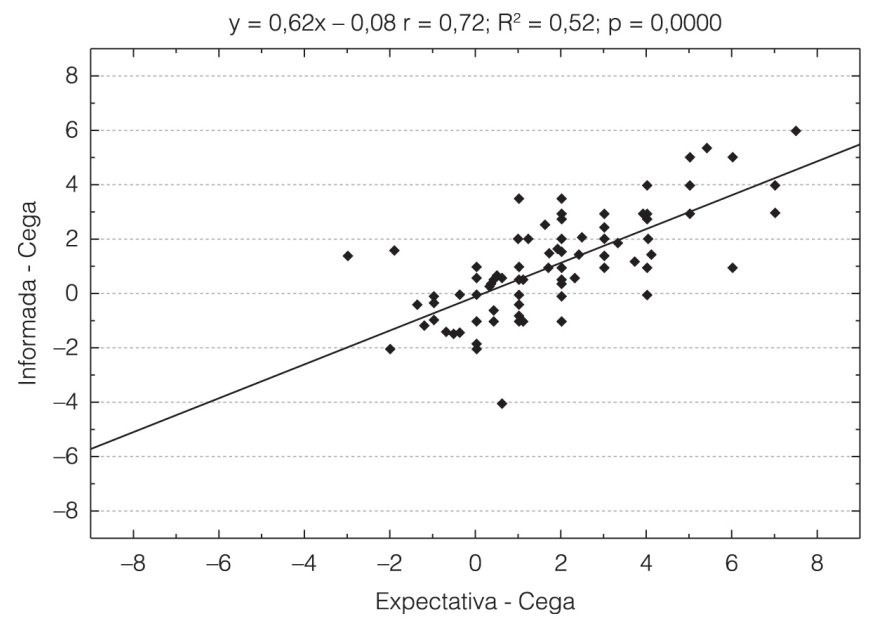

Figura 1. Modelo ajustado para o efeito da expectativa gerada pelas características não sensoriais na aceitação do café solúvel convencional (produto A) considerando-se as diferenças nas notas em diferentes condições de avaliação (expectativa - cega $x$ informada - cega).

qualidade sensorial predomina sobre a expectativa, e para um quarto da equipe nenhum efeito (8\%) ou um efeito obscuro (17\%) foi determinado.

Para o café solúvel adicionado de café torrado e moído micronizado (B), apesar da boa aceitação do produto na avaliação cega, foi observado que a embalagem não influenciou na expectativa (Tabelas 3 e 4). Combinando-se a informação desse teste às informações qualitativas levantadas no grupo de foco (item 3.1), pode-se dizer que a embalagem não influenciou positivamente devido ao menor interesse gerado pela sua aparência e material, ou mesmo a dificuldade no entendimento do conceito do produto.

Arruda et al. (2006), em um estudo sobre o impacto da embalagem e suas informações na aceitação dos cafés torrado e moído do tipo convencional, orgânico e descafeinado, relataram também a ocorrência de desconfirmação negativa e assimilação da expectativa para o produto convencional, enquanto não houve influência das características da embalagem sobre a aceitabilidade dos cafés com diferencial. Corso (2013), estudando cafés solúveis enriquecidos com antioxidantes, produto inexistente no mercado brasileiro, relatou que a embalagem de um deles, cujo design era moderno, apresentou efeito positivo para o produto; e que essa expectativa foi assimilada, demonstrando a importância da embalagem para a aceitação do consumidor quando um novo produto ou conceito está sendo proposto.

Assim, para um produto novo no mercado e que possui um conceito diferenciado (B) seria interessante que a embalagem gerasse uma maior expectativa, pelo menos equivalente à do café solúvel convencional.

\section{Conclusões}

A bebida do café solúvel adicionado de café torrado micronizado tem boa aceitação sensorial, similar à do café solúvel convencional.

Somente para o produto convencional, a aceitação da bebida é influenciada por características e informações da embalagem, pois o consumidor assimila a alta expectativa gerada pela maior familiaridade com o produto ou embalagem, aumentando sua aceitação na avaliação informada.

Há dificuldade em identificar, pela embalagem, o produto novo como sendo um café solúvel, mostrando a necessidade de deixar claro o conceito e diferencial do produto. Sugere-se uma embalagem mais similar à do café solúvel convencional (cores e ilustrações) e com informações claras quanto ao conceito e diferencial do produto, como a proximidade sensorial com café torrado e moído e facilidade no preparo de café solúvel.

\section{Agradecimentos}

Ao Conselho Nacional de Desenvolvimento Científico e Tecnológico (CNPq), pelo suporte financeiro.

\section{Referências}

ARRUDA, A. C.; DELLA LUCIA, S. M.; DIAS, B. R. P.; MINIM, V. P. R. Cafés Convencional, Orgânico e Descafeinado: Impacto da Informação na sua Aceitação. Revista Brasileira de Armazenamento, Viçosa, n. 9, p. 94-99, 2006. Especial Café.

ASSOCIAÇÃO BRASILEIRA DA INDÚSTRIA DE CAFÉ - ABIC. Tendências de Consumo de Café - VIII. São Paulo: ABIC, 2010. 108 p. Disponível em: <http://www.abic.com.br/publique/ media/EST_PESQTendenciasConsumo2010.pdf>. Acesso em: 06 out. 2014.

BALIEIRO, S. Nestlé Apresenta Duogrão, o Café para Preparar Sem Coador e Sem Mudar o Sabor. Época Negócios, 03 abr. 2012. Disponível em: <http://epocanegocios.globo.com/ Informacao/Acao/noticia/2012/04/nestle-apresenta-cafe-parapreparar-sem-coador-e-sem-mudar-o-sabor.html>. Acesso em: 06 out. 2014

BARBOSA, L.; MADI, L.; TOLEDO, M. A.; REGO, R. A. As Tendências da Alimentação. In: BRASIL Food Trends 2020. São Paulo: FIESP; ITAL, 2010. p. 39-47.

BEHRENS, J. H.; VILLANUEVA, N. D. M.; SILVA, M. A. A. P. Effect of Nutrition and Health Claims on the Acceptability of Soyamilk Beverages. International Journal of Food Science and Technology, Oxford, v. 42, n. 1, p. 50-56, 2007. http://dx.doi. org/10.1111/j.1365-2621.2006.01206.x

BUREAU DE INTELIGÊNCIA COMPETITIVA DO CAFÉ. Relatório Internacional de Tendências do Café, v. 3, n. 8, p. 1-15, 2014. Disponível em: <http://www.icafebr.com.br/publicacao/ Relatorio\%20v3\%20n8.pdf>. Acesso em: 06 out. 2014. 
Efeito das informações e características da embalagem na expectativa e aceitação de café solúvel torrado micronizado FRANCISCO, J. S. et al.

CAPORALE, G.; MONTELEONE, E. Influence of Information About Manufacturing Process on Beer Acceptability. Food Quality and Preference, Barking, v. 15, n. 3, p. 271-278, 2004.

COMPANHIA NACIONAL DE ABASTECIMENTO - CONAB. Perspectivas para a Agropecuária. Brasília: CONAB, 2014. v.

2. Disponível em: <http://www.conab.gov.br/OlalaCMS/uploads/ arquivos/14_09_10_18_03_00_perspectivas_2014-15.pdf>. Acesso em: 06 out. 2014.

CORSO, M. P. Café Solúvel Enriquecido com Antioxidantes Naturais do Café Verde: Estudo de Mercado, Desenvolvimento e Caracterização. 2013. 152 f. Tese (Doutorado em Ciência de Alimentos)-Departamento de Ciência e Tecnologia de Alimentos, Universidade Estadual de Londrina, Londrina, 2013. Disponível em: <file:///C:/Users/adm/Downloads/Corso_Marin\%C3\%AAs_P_ Dr_2013.pdf>. Acesso em: 06 out. 2014.

DELIZA, R.; MACFIE, H.; FERIA-MORALES, A.; HEDDERELY, D. The Effect of Consumer Expectation on the Evaluation of Instant Coffee. Brazilian Journal of Food Technology, Campinas, v. 3, n. 1, p. 97-105, 2000.

DELLA LUCIA, S. M.; MINIM, V. P. R.; MINIM, L. A.; SILVA, C. H. O. Características Visuais da Embalagem de Café no Processo de Decisão de Compra pelo Consumidor. Ciência e Agrotecnologia, Lavras, v. 33, p. 1758-1764, 2009. Número Especial.

DELLA LUCIA, S. M.; MINIM, V. P. R.; SILVA, C. H. O.; MINIM, L. A. Fatores da Embalagem de Café Orgânico Torrado e Moído na Intenção de Compra do Consumidor. Ciência e Tecnologia de Alimentos, Campinas, v. 27, n. 3, p. 485-491, 2007. http:// dx.doi.org/10.1590/S0101-20612007000300010

DUTCOSKY, S. D. Métodos Afetivos ou Subjetivos. In: DUTCOSKY, S. D. Análise sensorial de alimentos. 4. ed. Curitiba: Champagnat, 2013. cap. 5, p. 295-355.
KOBAYASHI, M. L. Caracterização Sensorial de Cafés Solúveis Comerciais e Estudo do Impacto de Embalagens na Intenção de Compra. 2012. 74 f. Dissertação (Mestrado em Ciência de Alimentos)-Departamento de Ciência e Tecnologia de Alimentos, Universidade Estadual de Londrina, Londrina, 2012. Disponível em: <file://C:/Users/adm/Downloads/Kobayashi_ Marcela_L_Me_2012.pdf>. Acesso em: 06 out. 2014.

KOBAYASHI, M. L.; BENASSI, M. T. Caracterização Sensorial de Cafés Solúveis Comerciais por Perfil Flash. Semina: Ciências Agrárias, Londrina, v. 33, suplemento 2, p. 3081-3092, 2012.

LANGE, C.; ROUSSEAU, F.; ISSANCHOU, S. Expectation, Liking and Purchase Behaviour Under Economical Constraint. Food Quality and Preference, Barking, v. 10, n. 1, p. 31-39, 1999.

NORONHA, R. L. F.; DELIZA, R.; SILVA, M. A. A. P. A Expectativa do Consumidor e seus Efeitos na Avaliação Sensorial e Aceitação de Produtos Alimentícios. Alimentos e Nutrição, Araraquara, v. 16, n. 3, p. 299-308, 2005.

OLIVEIRA, A. L.; CABRAL, F. A.; EBERLIN, M. N.; CARDELLO, H. M. A. B. Sensory Evaluation of Black Instant Coffee Beverage with Some Volatile Compounds Present in Aromatic Oil from Roasted Coffee. Ciência e Tecnologia de Alimentos, Campinas, v. 29 , n. 1, p. 76-80, 2009. http://dx.doi.org/10.1590/S010120612009000100012

STATSOFT. Statistica for Windows: Computer Program Manual. Versão 7.1. Tulsa: Software Inc., 2006.

STEFANI, G.; ROMANO, D.; CAVICCHI, A. Consumer Expectations, Liking and Willingness to Pay for Specialty Foods: Do Sensory Characteristics Tell the Whole Story? Food Quality and Preference, Barking, v. 17, n. 1, p. 53-62, 2006.

VILlanueVA, N. D. M.; PetenAte, A. J.; SilvA, M. A. A. P. Performance of the Hybrid Hedonic Scale as Compared to the Traditional Hedonic, Self-adjusting and Ranking Scales. Food Quality and Preference, Barking, v. 16, n. 8, p. 691-703, 2005. 